Article

\title{
Integrated Multifunctional Laryngoscope for Medical Diagnosis and Treatment
}

\author{
Shanshan Liang ${ }^{1, *}$, Xinyu Li ${ }^{1}$, Jiajing Kang ${ }^{1}$, Jiebin Zou ${ }^{1}$, Faya Liang ${ }^{2}$ and Jun Zhang ${ }^{1,3, *}$ (D) \\ 1 School of Electronics and Information Technology, Sun Yat-sen University, Guangzhou 510006, China; \\ lixinyu9@mail.sysu.edu.cn (X.L.); kangjj3@mail2.sysu.edu.cn (J.K.); zoujb3@mail2.sysu.edu.cn (J.Z.) \\ 2 Department of Otorhinolaryngology-Head\&Neck Surgery, Sun Yat-Sen Memorial Hospital, \\ Sun Yat-Sen University, Guangzhou 510006, China; liangfy3@mail.sysu.edu.cn \\ 3 School of Artificial Intelligence, Guilin University of Electronic Technology, Guilin 541004, China \\ * Correspondence: liangshsh@mail.sysu.edu.cn (S.L.); junzhang8819@gmail.com (J.Z.)
}

Received: 15 September 2020; Accepted: 23 October 2020; Published: 25 October 2020

\begin{abstract}
Laryngeal lesions can cause great inconvenience to patients. Early diagnosis and corresponding treatments are critical to the survival of patients. However, the diagnosis and precise removal of tumors remain a challenge under the use of a white light laryngoscope. In this work, an integrated, multifunctional laryngoscope was designed and tested for the imaging evaluation and precision laser surgery for laryngeal tissue. This integrated diagnostic and therapeutic endoscopic system included two imaging modes (i.e., optical coherence tomography and white light endoscopy) and a laser ablation treatment mode. The endoscope had a common-path design to ensure that the same position could be imaged and treated simultaneously. The ex vivo porcine larynx experimental results showed that the system imaging modes could simultaneously acquire both superficial and cross-sectional images of the sample tissue, and the ablation treatment could be performed under imaging guidance. This multifunctional laryngoscope has great potential for the early diagnosis of and accurate laser ablation surgery for laryngeal tumors.
\end{abstract}

Keywords: integrated multifunctional laryngoscope; optical coherence tomography; white light endoscope; laser ablation

\section{Introduction}

The larynx plays a vital role in airway protection, respiration, and phonation. Therefore, laryngeal lesions, such as laryngeal cancer, can cause great inconvenience and even fatality to patients $[1,2]$. Improvements in disease management, including earlier diagnosis and better use of comprehensive treatment options, can improve the survival rate of laryngeal cancer to some extent [3-6]. In the diagnosis of laryngeal lesions, the white light laryngoscope [7], which can provide superficial morphology information, can be used during biopsy [8]. However, some early-stage laryngeal cancers are very similar to benign diseases in terms of morphology and may occur in the epithelial layer [9], where they cannot be distinguished by a white light endoscope. False-negative results or voice damage may occur due to medical errors [10,11]. Therefore, a more reliable and accurate cross-sectional imaging technology is needed.

Optical coherence tomography (OCT) is an emerging noninvasive cross-sectional imaging technique $[12,13]$ that has been widely used in a variety of clinical studies [14-16]. Combining OCT with laryngoscopy can simultaneously acquire superficial morphology information and cross-sectional structure information from the examined tissue. Sergeev and Gelikonov et al. integrated the fiber-based sample arm of OCT into the lumen of a standard endoscopic device; they obtained images of mucous membranes in the larynx, revealing that the technique could be used for precise guidance in the early 
diagnosis and excisional biopsy of tumors $[17,18]$. Guo and Yu et al. developed a rigid OCT probe that could be used with a laryngoscope for office-based patient examination without anesthesia $[19,20]$. However, this system was a "double-barreled" configuration, and the device was large and difficult to operate. A laryngoscope with an integrated OCT beam path was presented by Wisweh et al. [21,22]; this single-channel system enabled simultaneous OCT and video laryngoscopy imaging. However, this probe diameter was $10 \mathrm{~mm}$ and contained excessive lenses, which would lead to a great loss of the OCT signal. Therefore, a more compact and easy-to-handle dual imaging modality laryngoscope is needed.

OCT can also be used to evaluate laser surgery for laryngeal lesions [23-26]. Boppart et al. used a spectroscopic element to couple the OCT imaging path with the ablation path; they performed real-time OCT imaging to guide the surgical laser ablation of various tissue types [27]. Shakhov et al. showed that the integration of OCT and laser ablation enhanced the efficacy of laryngeal organ-preserving surgery [28]. Guided by OCT imaging, the accuracy of the treatment position could be further ensured, and surgical errors could be avoided. However, the diagnostic system is often independent of the treatment system.

In this work, an integrated multifunctional laryngoscope for medical diagnosis and treatment is presented. The two imaging modes of OCT, i.e., a white light endoscope and a laser ablation treatment mode, are integrated into a common-path system by sharing one probe. The superficial and cross-sectional images can be acquired simultaneously and used for preoperative diagnosis and postoperative evaluation. In addition, under the guidance of dual-mode imaging, the position and depth of the laser ablation treatment system could be accurately controlled. The preliminary results show the potential of this multifunctional integrated endoscopic system for the diagnosis and treatment of laryngeal lesions.

\section{Materials and Methods}

\subsection{System Design}

Figure 1 shows a schematic of the integrated multifunctional laryngoscope. The white light endoscope and the OCT system were coupled to the probe by two $45^{\circ}$ dichroic mirrors, while the laser ablation treatment system was in a straight line. The endoscope was a common-path structure.

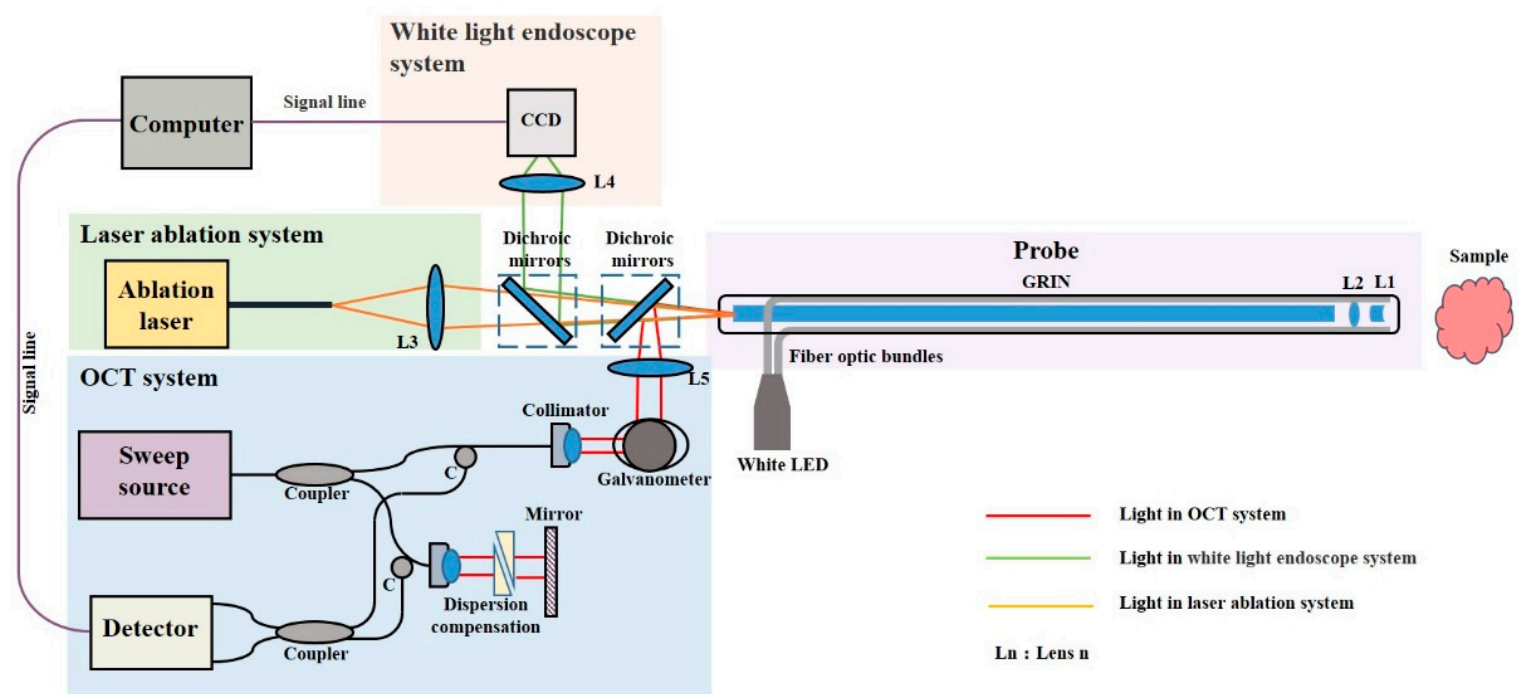

Figure 1. Schematic of the integrated multifunctional laryngoscope. L\#: lens; GRIN: Gradient-index lens; CCD: charge-coupled device; C: circulator.

The OCT unit was a swept-source OCT system with an A-scan rate of $100 \mathrm{kHz}$ (HSL-20-100, Santec Corporation, Japan). The full spectral sweep range was $87 \mathrm{~nm}$ centered at $1310 \mathrm{~nm}$, which had 
lower scattering than at a shorter wavelength $[29,30]$. The incident light from the source was coupled into an 80:20 ratio coupler; $80 \%$ entered the sample endoscope and $20 \%$ entered the reference arm. In the reference arm, the light was reflected by the mirror and propagated back to the interferometer. The collimated beam in the sample arm was scanned by a two-dimensional galvanometer (GVS002, Thorlabs, Newton, NJ, USA) and focused with an achromatic doublet L5. The beam was guided to the probe by a customized dichroic mirror and then focused on the sample with a working distance of $15 \mathrm{~mm}$. The OCT interference spectrum was acquired by using a balanced detector (PBD430c, Thorlabs, Newton, NJ, USA) and a high-speed digitizer (ATS9360, Alazar Technologies, Pointe-Claire, QC, Canada ).

The white light imaging unit consisted of the probe, the proximal objective, and the camera. Illumination light from a white LED was transmitted to the sample through fiber optic bundles. The reflected light from the sample surface was deflected using a customized dichroic mirror that passed the proximal objective onto the CMOS (Complementary Metal Oxide Semiconductor) sensor (CatchBEST Optoelectronic Equipment, Beijing, China) with $1024 \times 1248$ pixels.

For the laser ablation unit, the medical ablation laser (Leonardo Dual 45, Biolitec biomedical technology, Jena, Germany ) output beam was guided to the system via a multimode fiber and then coupled to the probe by a doublet L3, as shown in Figure 1. The ablation laser had dual wavelengths at 980 and $1470 \mathrm{~nm}$, and the maximal output power was $45 \mathrm{~W}$. The ratio of power between the two wavelengths could be adjusted for different kinds of applications.

\subsection{Probe Design}

The probe had a common path design, including the distal objective and the relay system. As shown in Figure 2, there were two lenses in the distal objective: a plano-concave lens L1 with a focal length of $-9.8 \mathrm{~mm}$ and an achromatic doublet $\mathrm{L} 2$ with a focal length of $10 \mathrm{~mm}$. The interval between the two lenses was $15 \mathrm{~mm}$. A GRIN (Gradient-index) lens (Gradient Lens Corporation, Rochester, NY, USA) with a length of one pitch $(218 \mathrm{~mm})$ was used as a relay. The homemade optical fiber bundle was placed between the inner metal tube and the outer metal tube and was connected to a LED white light source, which provided additional lighting for the white light endoscope; the fiber used for illumination is a multimode polymers fiber bundle with a $600 \mu \mathrm{m}$ core. The diameter and length of the probe were 8 and $250 \mathrm{~mm}$, respectively. The working distance of the probe was set to $15 \mathrm{~mm}$.

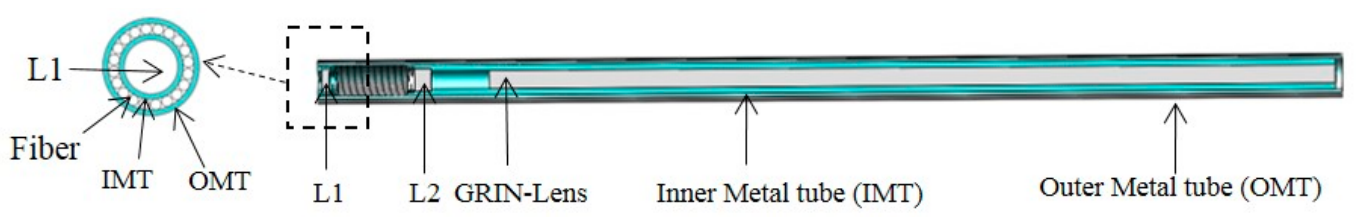

Figure 2. Front (left) and cross-sectional (right) views of the probe. L1: plano-concave lens $-9.8 \mathrm{~mm}$; L2: achromatic doublet $10 \mathrm{~mm}$; LMT: inner metal tube; OMT: outer metal tube.

\section{Experiments and Results}

\subsection{Evaluation of System Parameters}

The parameters of the imaging and ablation unit were tested at the designed working distance of $15 \mathrm{~mm}$. As shown in Figure 3A, for the white light endoscope, the imaging range was $14 \mathrm{~mm}$, and the resolution was $32 \mathrm{lp} / \mathrm{mm}$ at the central area by using a test target (1951 USAF test target). The OCT system transverse resolution was $121.7 \mu \mathrm{m}$ at the central field of view of the OCT system. The axial resolution was $12 \mu \mathrm{m}$, which was obtained by analyzing the point spread function, as shown in Figure 3B. Since the light intensity decayed dramatically at the edge of the scanning area, the scanning range of the OCT B-scan was set to $10 \mathrm{~mm}$, which was slightly less than that of the white light endoscope. The B-scan rate was 100 frames/second. This imaging range coincided with that of the white light endoscope. The beam diameter of the ablation laser was $2200 \mu \mathrm{m}$ at a working distance 
of $15 \mathrm{~mm}$, as shown in Figure 3C. In conventional laser surgery, the light beam diverges from the multimode fiber. At a distance of $5 \mathrm{~mm}$, the beam diameter is usually larger than $2000 \mu \mathrm{m}$. Therefore, this spot diameter at the object distance of $15 \mathrm{~mm}$ is acceptable for laser ablation.
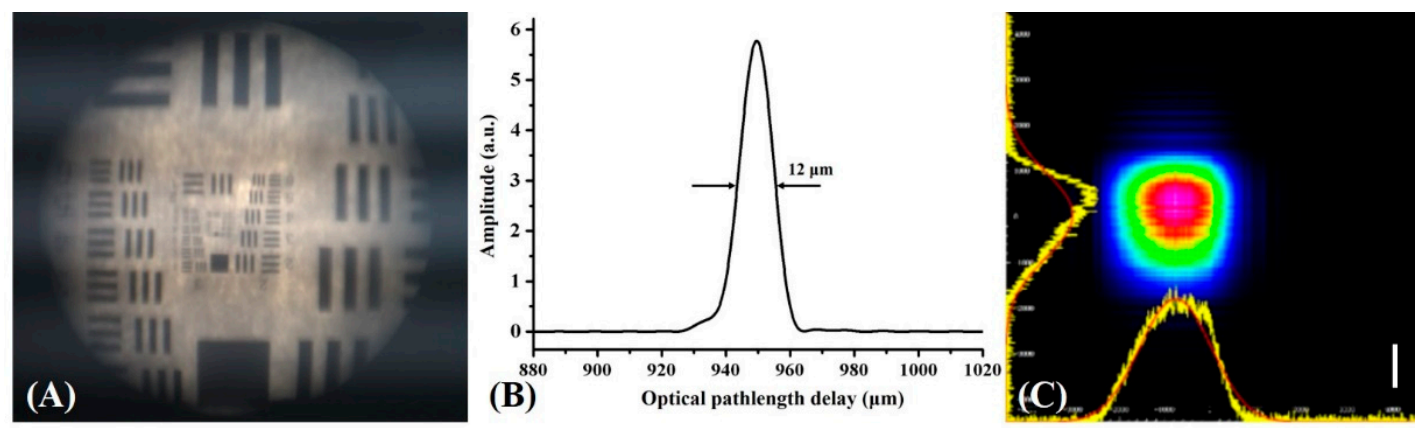

Figure 3. (A) The test target white light image at $15 \mathrm{~mm}$; (B) Optical coherence tomography (OCT) point spread function (PSF); (C) laser ablation beam profile at $15 \mathrm{~mm}$ (scale bar: $1000 \mu \mathrm{m}$ ).

\subsection{Ex Vivo Porcine Larynx Experiments:}

The ex vivo porcine larynx was imaged before and after laser ablation. In total, over 25 tests on three ex vivo porcine larynx samples were carried out. The imaging area is indicated in Figure 4A; the corresponding white light image of the laryngeal surface is shown in Figure 4B; and the cross-sectional OCT image of the black line area is shown in Figure 4C. In the OCT image, three layers can be distinguished: the epithelial layer (E), the mucosa lamina propria (LP), and the smooth muscle layer (SM). The boundary was obvious. Moreover, the basement membrane (BM) in the OCT image was clear, which was the boundary between the epithelial layer and the intrinsic mucosa layer. Some studies have shown that malignant lesions lead to the disappearance of the BM [17,31,32]. Therefore, the coaxial dual-modality images could provide more useful information for diagnosis within one test process.

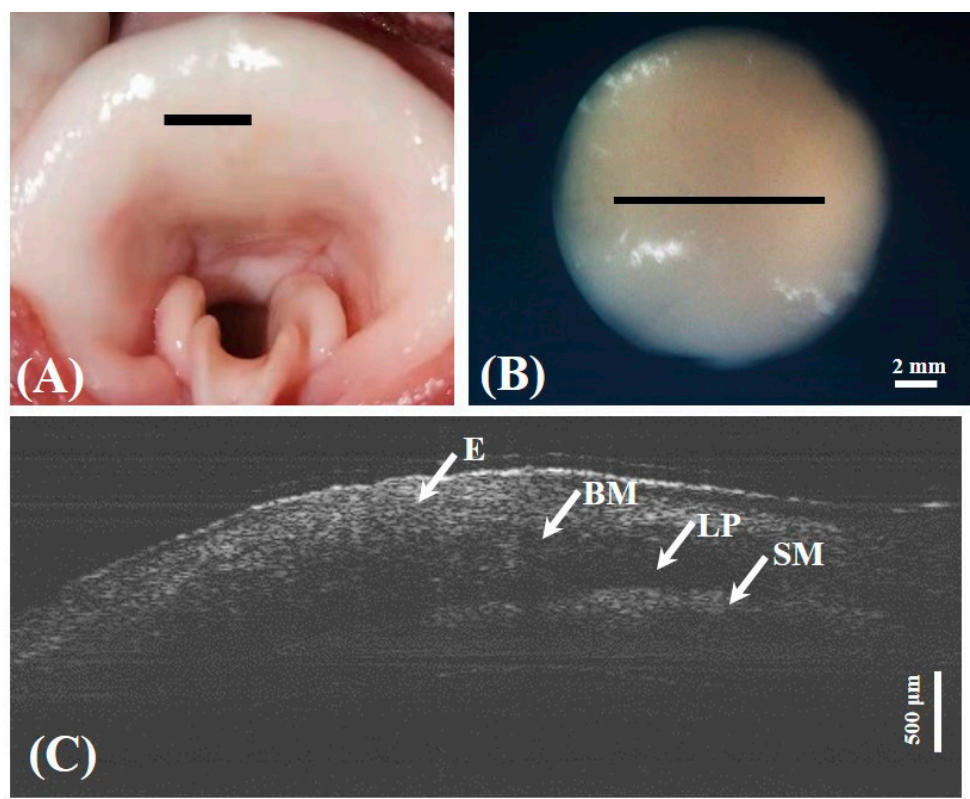

Figure 4. Ex vivo porcine larynx experiment. (A) Picture of the ex vivo porcine larynx; (B) white light laryngoscope image; (C) OCT image of the black line region. E: epithelial layer; LP: mucosa lamina propria; SM: smooth muscle layer; BM: basement membrane.

An ablation power of $15 \mathrm{~W}$ was utilized to test the ablation function. The ablation zone (AZ) in Figure 5A indicates the ablation area. After ablation, a round ablation spot can be seen in the white 
light image. In the OCT image, the ablation effect and boundary can be presented more accurately, as shown in Figure 5B. The preliminary results showed that the multimodal endoscope could be a useful tool for an accurate guiding of laser ablation surgery and could evaluate the ablation effect after surgery.
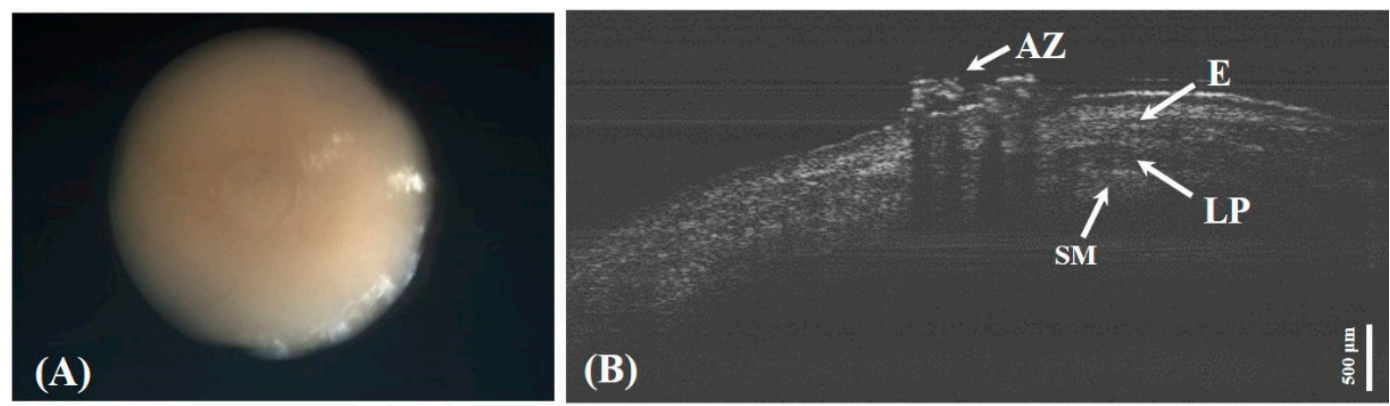

Figure 5. (A) White light laryngoscope image after laser ablation and (B) OCT image after laser ablation.

\section{Discussion}

A coaxial multifunctional endoscopic system for the diagnosis and treatment of laryngeal lesions was developed. The cross-sectional OCT imaging, superficial white light laryngoscope, and laser ablation function were integrated into one signal probe with a diameter of $8 \mathrm{~mm}$ and length of $250 \mathrm{~mm}$. With this coaxial design, the imaging modes and laser ablation position could register more accurately and reduce the examination time compared to the single-modality probe $[7,17]$.

However, some limits still need to be improved. The $8 \mathrm{~mm}$ diameter is suitable for the ex vivo study, but for the in vivo study, a smaller diameter is needed since the commonly used laryngoscope diameter is around $5 \mathrm{~mm}$ [33]. We plan to use smaller illumination fiber and thinner wall tubing to solve this problem. The lateral resolution of OCT was about $120 \mu \mathrm{m}$. It was not as good as the single-channel OCT endoscope [34], which is usually around tens of microns. This was because we wanted to ensure a large field of view of the white light imaging. In the future, we hope to find a balance between the field of view and the lateral resolution. For the ex vivo experiments, the A-scan rate was $100 \mathrm{kHz}$. It was fast enough to acquire images without large motion artifacts. However, for in vivo studies, the A-scan rate could be further increased to $200 \mathrm{kHz}$, and a motion feedback function could further increase system stability [35].

\section{Conclusions}

In this work, a multifunctional laryngoscope was designed and fabricated. OCT and white light imaging and laser ablation surgery function were integrated into one common-path probe. The preliminary ex vivo porcine larynx experimental results showed that this multifunctional imaging and laser ablation endoscope could be a useful tool for diagnosing laryngeal lesions and accurate positioning during laser ablation surgery procedure. We hope to keep improving the performance of the system and try to utilize the system in clinical studies.

Author Contributions: Conceptualization, S.L. and J.Z. (Jun Zhang); methodology, S.L., X.L., and J.K.; software, X.L.; supervision, S.L. and J.Z. (Jun Zhang); validation, X.L., J.K., and J.Z. (Jiebin Zou); resources, F.L.; writing-original draft, S.L. and X.L.; review and editing, S.L. All authors have read and agreed to the published version of the manuscript.

Funding: This research was funded by the National Natural Science Foundation of China (No. 61975246, 61505267) and the Science and Technology Program of Guangzhou (No. 201903010065) and Research Fund for Guangxi Distinguished Experts.

Conflicts of Interest: The authors declare no conflict of interest. 


\section{References}

1. Lewis, C.M.; Laccourreye, O.; Weber, R.S.; Holsinger, F.C. Cancers of the Larynx: Tis, T1, T2 Evaluation and Management. Head and Neck Cancer; Springer: New York, NY, USA, 2011.

2. Rudolph, E.; Dyckhoff, G.; Becher, H.; Dietz, A.; Ramroth, H. Effects of tumour stage, comorbidity and therapy on survival of laryngeal cancer patients: A systematic review and a meta-analysis. Eur. Arch. Oto-Rhino-L 2011, 268, 165-179. [CrossRef] [PubMed]

3. Liu, Y.; Zhao, Q.; Ding, G.; Zhu, Y.; Li, W.; Chen, W. Incidence and mortality of laryngeal cancer in China, 2008-2012. Chin. J. Cancer Res. 2018, 30, 299-306. [CrossRef]

4. Hoffman, H.T.; Porter, K.; Karnell, L.H.; Cooper, J.S.; Weber, R.S.; Langer, C.J.; Ang, K.; Gay, G.; Stewart, A.; Robinson, R.A. Laryngeal cancer in the United States: Changes in demographics, patterns of care, and survival. Laryngoscope 2006, 116, 1-13. [CrossRef] [PubMed]

5. Lee, L.A.; Cheng, A.J.; Fang, T.J.; Huang, C.G.; Liao, C.T.; Chang, J.T.; Li, H.Y. High incidence of malignant transformation of laryngeal papilloma in Taiwan. Laryngoscope 2008, 118, 50-55. [CrossRef] [PubMed]

6. Chu, E.A.; Kim, Y.J. Laryngeal cancer: Diagnosis and preoperative work-up. Otolaryng Clin. N. Am. 2008, 41, 673-695. [CrossRef] [PubMed]

7. Davaris, N.; Kropf, S.; Arens, C. Influence of prior laryngeal surgery on the diagnostic value of laryngeal endoscopy. Laryngo-Rhino-Otologie 2018, 97, 10263.

8. Lin, K.; Zheng, W.; Lim, C.M.; Huang, Z. Real-time in vivo diagnosis of laryngeal carcinoma with rapid fiber-optic Raman spectroscopy. Biomed. Opt. Express 2016, 7, 3705-3715. [CrossRef]

9. Song, P. Assessment of vocal cord function and voice disorders. In Principles and Practice of Interventional Pulmonology; Ernst, A., Herth, F., Eds.; Springer: New York, NY, USA, 2013.

10. Bergström, L.; Ward, E.C.; Finizia, C. The impact of laryngeal biopsy on voice outcomes: A pilot study. Otorhinolaryngol. Head Neck Surg. 2016, 1, 33-37. [CrossRef]

11. Wohl, D.L. Nonsurgical management of pediatric vocal fold nodules. Arch. Otolaryngol. Head Neck Surg. 2005, 131, 68-70. [CrossRef]

12. Huang, D.; Swanson, E.A.; Lin, C.P.; Schuman, J.S.; Stinson, W.G.; Chang, W.; Hee, M.R.; Flotte, T.; Gregory, K.; Puliafito, C.A. Optical coherence tomography. Science 1991, 254, 1178-1181. [CrossRef]

13. Fercher, A.F.; Drexler, W.; Hitzenberger, C.K.; Lasser, T. Optical coherence tomography—Principles and applications. Rep. Prog. Phys. 2003, 66, 239-303. [CrossRef]

14. Costa, R.A.; Skaf, M.; Melo, L.A.S.; Calucci, D.; Cardillo, J.A.; Castro, J.C.; Huang, D.; Wojtkowski, M. Retinal assessment using optical coherence tomography. Prog. Retin. Eye Res. 2006, 25, 325-353. [CrossRef] [PubMed]

15. Tsai, T.H.; Lee, H.C.; Ahsen, O.O.; Liang, K.; Giacomelli, M.G.; Potsaid, B.M.; Tao, Y.K.; Jayaraman, V.; Figueiredo, M.; Huang, Q.; et al. Ultrahigh speed endoscopic optical coherence tomography for gastroenterology. Biomed. Opt. Express 2014, 5, 4387-4404. [CrossRef]

16. Sinclair, H.; Bourantas, C.; Bagnall, A.; Mintz, G.S.; Kunadian, V. OCT for the identification of vulnerable plaque in acute coronary syndrome. JACC Cardiovasc. Imaging 2015, 8, 198-209. [CrossRef]

17. Sergeev, A.; Gelikonov, V.; Gelikonov, G.; Feldchtein, F.; Kuranov, R.; Gladkova, N.; Shakhova, N.; Snopova, L.; Shakhov, A.; Kuznetzova, I.; et al. In vivo endoscopic OCT imaging of precancer and cancer states of human mucosa. Opt. Express 1997, 1, 432-440. [CrossRef] [PubMed]

18. Gelikonov, V.M.; Gelikonov, G.V.; Gladkova, N.D.; Shahova, N.M.; Feldchtein, F.I.; Sergeev, A.M.; Imalux, C. Optical Coherent Tomography Apparatus, Fiberoptic Lateral Scanner and Method for Studying Biological Tissues In Vivo. U.S. Patent No. 6,608,684, 19 August 2003.

19. Guo, S.; Hutchison, R.; Jackson, R.P.; Kohli, A.; Sharp, T.; Orwin, E.; Haskell, R.; Chen, Z.; Wong, B.J.F. Office-based optical coherence tomographic imaging of human vocal cords. J. Biomed. Opt. 2006, 11, 30501-30503. [CrossRef]

20. Yu, L.; Liu, G.; Rubinstein, M.; Saidi, A.; Wong, B.J.; Chen, Z. Office-based dynamic imaging of vocal cords in awake patients with swept-source optical coherence tomography. J. Biomed. Opt. 2009, 14, 64020. [CrossRef]

21. Wisweh, H.; Rohrbeck, N.; Krüger, A.; Kraft, M.; Aleksandrov, K.; Lubatschowski, H. In a laryngoscope for office-based imaging of human vocal folds using OCT. In Proceedings of the European Conference on Biomedical Optics, Munich, Germany, 14-18 June 2009; p. 73720I. 
22. Donner, S.; Bleeker, S.; Ripken, T.; Ptok, M.; Jungheim, M.; Krueger, A. Automated working distance adjustment enables optical coherence tomography of the human larynx in awake patients. J. Med. Imaging 2015, 2, 26003. [CrossRef]

23. Torkian, B.A.; Guo, S.; Jahng, A.W.; Liaw, L.H.; Chen, Z.; Wong, B.J. Noninvasive measurement of ablation crater size and thermal injury after CO2 laser in the vocal cord with optical coherence tomography. Otolaryngol. Head Neck Surg. 2006, 134, 86-91. [CrossRef]

24. Fleming, C.P.; Quan, K.J.; Rollins, A.M. Toward guidance of epicardial cardiac radiofrequency ablation therapy using optical coherence tomography. J. Biomed. Opt. 2010, 15, 41510. [CrossRef]

25. Murgu, S.D.; Colt, H.G.; Mukai, D.; Brenner, M. Multimodal imaging guidance for laser ablation in tracheal stenosis. Laryngoscope 2010, 120, 1840-1846. [CrossRef] [PubMed]

26. Tsai, T.H.; Zhou, C.; Tao, Y.K.; Lee, H.C.; Ahsen, O.O.; Figueiredo, M.; Kirtane, T.; Adler, D.C.; Schmitt, J.M.; Huang, Q.; et al. Structural markers observed with endoscopic 3-dimensional optical coherence tomography correlating with Barrett's esophagus radiofrequency ablation treatment response (with videos). Gastrointest. Endosc. 2012, 76, 1104-1112. [CrossRef] [PubMed]

27. Boppart, S.A.; Herrmann, J.; Pitris, C.; Stamper, D.L.; Brezinski, M.E.; Fujimoto, J.G. High-Resolution optical coherence tomography-guided laser ablation of surgical tissue. J. Surg. Res. 1999, 82, 275-284. [CrossRef] [PubMed]

28. Shakhov, A.V.; Terentjeva, A.B.; Kamensky, V.A.; Snopova, L.B.; Gelikonov, V.M.; Feldchtein, F.I.; Sergeev, A.M. Optical coherence tomography monitoring for laser surgery of laryngeal carcinoma. J. Surg. Oncol. 2001, 77, 253-258. [CrossRef] [PubMed]

29. Brezinski, M.E.; Tearney, G.J.; Bouma, B.E.; Izatt, J.A.; Hee, M.R.; Swanson, E.A.; Southern, J.F.; Fujimoto, J.G. Optical coherence tomography for optical biopsy. Properties and demonstration of vascular pathology. Circulation 1996, 93, 1206-1213. [CrossRef] [PubMed]

30. Parsa, P.; Jacques, S.L.; Nishioka, N.S. Optical properties of rat liver between 350 and 2200 nm. Appl. Opt. 1989, 28, 2325. [CrossRef] [PubMed]

31. Kraft, M.; Glanz, H.; von Gerlach, S.; Wisweh, H.; Lubatschowski, H.; Arens, C. Clinical value of optical coherence tomography in laryngology. Head Neck 2008, 30, 1628-1635. [CrossRef]

32. Wong, B.J.; Jackson, R.P.; Guo, S.; Ridgway, J.M.; Mahmood, U.; Su, J.; Shibuya, T.Y.; Crumley, R.L.; Gu, M.; Armstrong, W.B.; et al. In vivo optical coherence tomography of the human larynx: Normative and benign pathology in 82 patients. Laryngoscope 2005, 115, 1904-1911. [CrossRef]

33. Liao, C.C.; Liu, F.C.; Li, A.H.; Yu, H.P. Video laryngoscopy-assisted tracheal intubation in airway management. Expert Rev. Med. Devices 2018, 15, 265-275. [CrossRef]

34. Gora, M.J.; Suter, M.J.; Tearney, G.J.; Li, X. Endoscopic optical coherence tomography: Technologies and clinical applications [Invited]. Biomed. Opt. Express 2017, 8, 2405. [CrossRef]

35. Kraus, M.F.; Potsaid, B.; Mayer, M.A.; Bock, R.; Baumann, B.; Liu, J.J.; Hornegger, J.; Fujimoto, J.G. Motion correction in optical coherence tomography volumes on a per A-scan basis using orthogonal scan patterns. Biomed. Opt. Express 2012, 3, 1182. [CrossRef] [PubMed]

Publisher's Note: MDPI stays neutral with regard to jurisdictional claims in published maps and institutional affiliations.

(C) 2020 by the authors. Licensee MDPI, Basel, Switzerland. This article is an open access article distributed under the terms and conditions of the Creative Commons Attribution (CC BY) license (http://creativecommons.org/licenses/by/4.0/). 